\title{
THE PSYCHOLOGICAL EFFECT OF FASHION COLOURS COLLECTIONS AND FASHION ORIGINALITY: AN EXPERIMENT ON FASHION DESIGN PROGRAM STUDENTS
}

\author{
Rehab Ragab Mahmoud Hassaan \\ Prof. Dr., University of Nizwa, Oman. Helwan University, Egypt, rehab.ragab@unizwa.edu.om
}

\begin{abstract}
Colour is a major element of fashion design, has a certain psychological effect on wearer and viewer. Fashion program students must be trained sufficiently and correctly for using colours in their designs. Within the author experience of teaching fashion designing at University of Nizwa, and with observing the importance and supremacy of black colour in outerwear Omani women Abaya, the author applied an experiment on fashion design program students, the objective of the experiment is to measure the effect of several fashion colour collections on the student's psychology, guiding students to the psychological effect of colours, and for encouraging them to integrate several colours when designing black abaya, it's a most challenging part for design a new fashion style for a conservative community. At the same time measuring and leading the students to designing originality, within designing by flat and $3 \mathrm{D}$ mixed colours ribbons on black velvet basic. The study followed the descriptive approach within designing and applying the study instrument, represented in opinion rating scale toward coloured fashion designs and the originality of proposed designs, the scale measured the psychological effect of (8), designs had been created by the author. The psychological effect behind fashion colours is classified into 2 thematic categories in current paper: a) the effect of rainbow colours fashion vs b) the effect of earthy colours fashion. The psychological effect behind fashion originality is classified into 2 thematic categories in current paper: a) the effect of decorating by flat ribbons vs b) the effect by decorating by 3D ribbons. The results indicated the tendency of the students toward rainbow colours collection with flat decorating ribbons. Results of current study may play a guiding role on colours effects studies and developing the aesthetics of producing new trend of Arabic black abaya in the future.
\end{abstract}

Keywords: Fashion psychological effect, fashion psychological experiment, fashion originality, 3D fashion, fashion colours psychology.

\section{INTRODUCTION}

Colour is critical to creating attractiveness, the use of colour has become an important expression of who we wear, how we feel and what we believe. (Kodzoman, 2019, p.1- 14) Human vision and perception contributes to how a colour appears to the individual. Perception is different to each person and is constantly changing due to the influence of a range of variables. (Cash, and others, 1989, P.349-355)

Many studies have been carried out on colour preferences phenomena, Frank and Giovich showed that an individual's behaviour can be influenced by the colour of their clothing, in their experiment they manipulated the colour of the subject's uniform (black or white), results the subjects who wear black uniforms were more aggressive. Adams and Osgood concluded that black is seen, in almost all cultures, as a colour of evil and death. (Adams, Osgood, 1973, P. 135-156) Vrij conducted two experiments to investigate the impact of black clothing on impression formation, results revealed that black clothing evokes negative impressions. (Verji, 1997, P.47-53).

Current study investigates the psychological and emotional effect of fashion colour collections on the visionary, the main goal is to train students of the fashion design program to recognise the importance and 
sensitivity of colour when designing, as well as the study investigates the psychological effect of seeing original fashion designs on students to raise their motivation to design and produce new and distinguished fashion trends, the distant target is to push the students to design a new fashion trend for the black Arabic abaya decorated with mixed- colours ribbons.

\section{PROBLEM}

The problem represents in the following questions:

1 - What is the psychological effect when viewing the different colour collections of fashion?

2- What is the psychological effect on students of the Fashion Program when viewing original fashion designs?

3- How possible is it to raise the motivation of the students of the Fashion Design Program to design a black Arabic abaya decorated with colourful cuts and colourful ribbons as a new trend of Gulf abayas?

\section{OBJECTIVES}

1- Identify the psychological effect of fashion colours on viewers, colour collections (rainbow colours) and (earthy colours).

2- Training students of the fashion design program to recognize psychological emotions when viewing the colours of fashion, and thus pay attention to the importance of selecting the proposed colours for their applied projects.

3- Identify the effect of viewing original fashion designs in raising the motivation to design and produce an innovative fashion trend among students of the Fashion Design Program.

4- Preparing for launching an original fashion trend of black Arab abaya that decorated by mixed colours cuts and mixed colours ribbons (tie and dye fabrics).

\section{SIGNIFICANCE}

1- Raising the efficiency of design programs students by engaging them in practical design experiences $j$

2- Training students in the Fashion Design Program on the sensitivity and importance of the psychological effect of colours collections supports these students in designing and producing successful fashion in the future.

3- Training students of fashion design programs on the importance of originality in designing and going beyond safe zone, this motivating them to excel when establishing their brands after graduation.

4- Opening the entrances for students of the Fashion Design program to establish new trends for the black Arabic abaya.

5- The results of the current study may benefit researchers in other fields, such as: color therapy - clothing therapy - creativity learning - design education.

\section{METHODOLOGY}

The study follows the descriptive approach by designing and applying the research instrument, which is an opinion scale that was applied to the study sample of Fashion Design Program students at the University of Nizwa - Sultanate of Oman, for the academic year 2020/2021.

\section{THE EXPERIMENT}

\subsection{Preparation of Experiment Proposed Fashion Designs}

The author designed (8) proposed fashion designs using black colour velvet as the basic, decorated the designs with mixed-colour ribbons (fabrics of tie and dye) in the form of ribbons in various widths and lengths. The used colourful fabrics had been dyed by students at the University- Fashion Design Program for Fall 2020 semester. The researcher selected two collections of colours:

The rainbow colour collection: yellow, red, green, blue, and orange, which are bright and strong colours, the second collection, which is a grouping of earth colours that are characterized by being faded, hazy, opaque, and weak, such as light blue and pale light purple - faded pink and beige. The researcher strengthened some ribbons with "Vaseline" for implementing 3D ribbons in the design.

The (8) designs were divided into (4) groups, so that each group conveys two designs, as follows: designs 
1+2 (fig. 1-2) a rainbow colour collection with flat coloured ribbons - designs 3+4 (fig. 3-4) a rainbow colour collection with 3D-coloured ribbons - designs 5+6 (fig.5-6) an earthy colour collection with flat coloured ribbons - designs 7+8 (fig. 7-8) an earthy colour collection with coloured 3D ribbons.

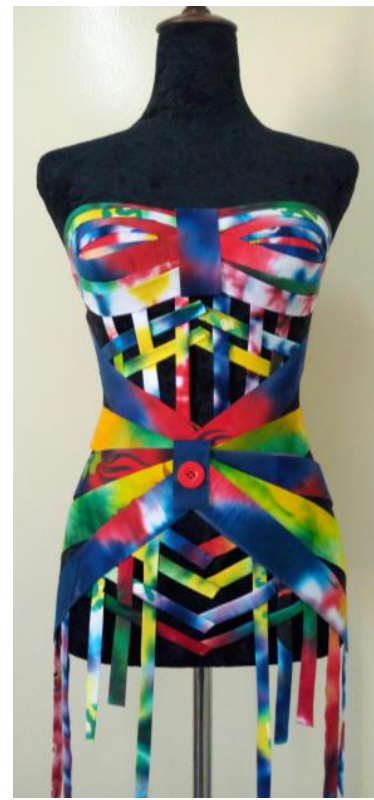

Fig. 1

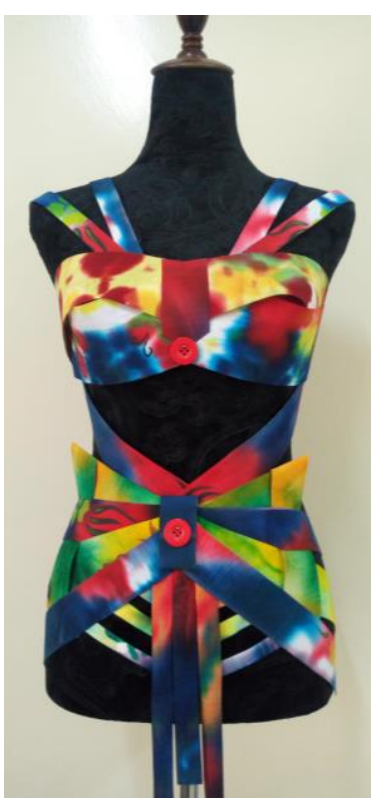

Fig. 2

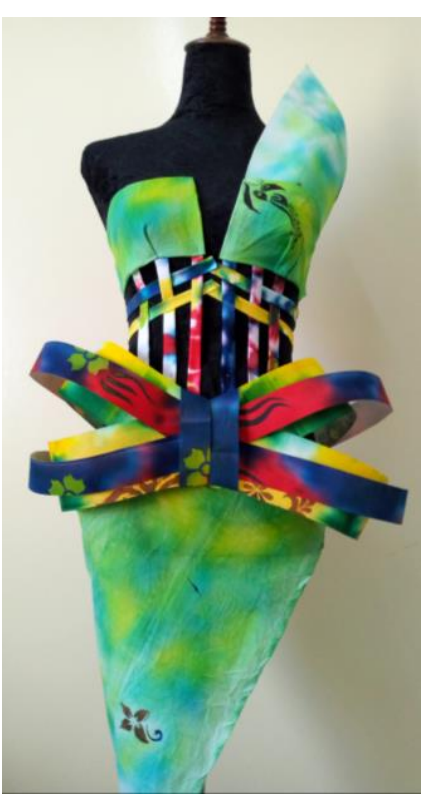

Fig. 3

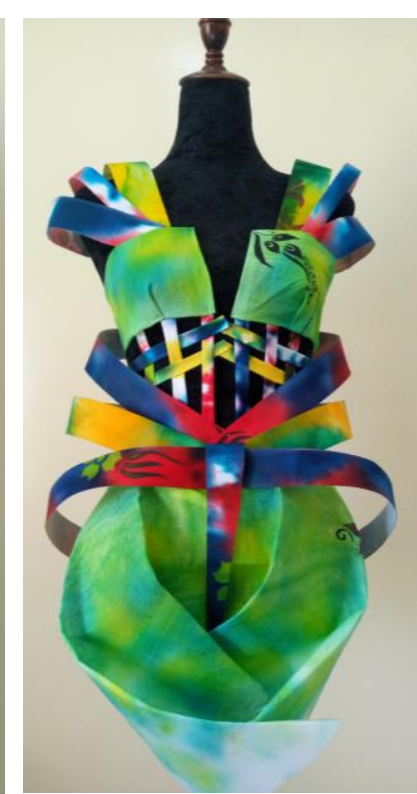

Fig. 4

(rainbow - 3D)

(rainbow - flat)

(rainbow -flat)

(rainbow - 3D)

by author.

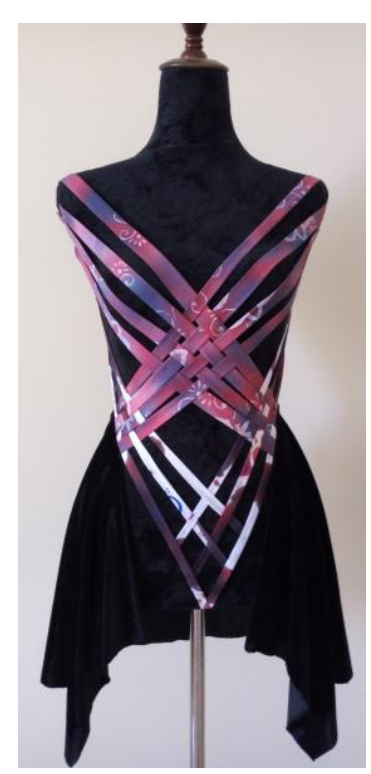

Fig. 5

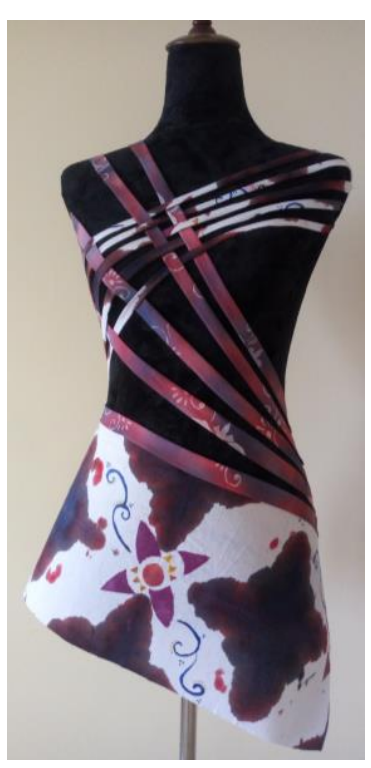

Fig. 6

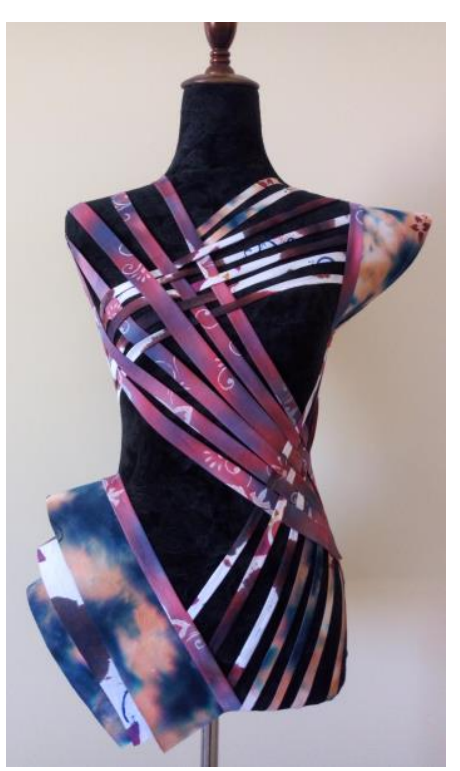

Fig. 7

(earthy - 3D)

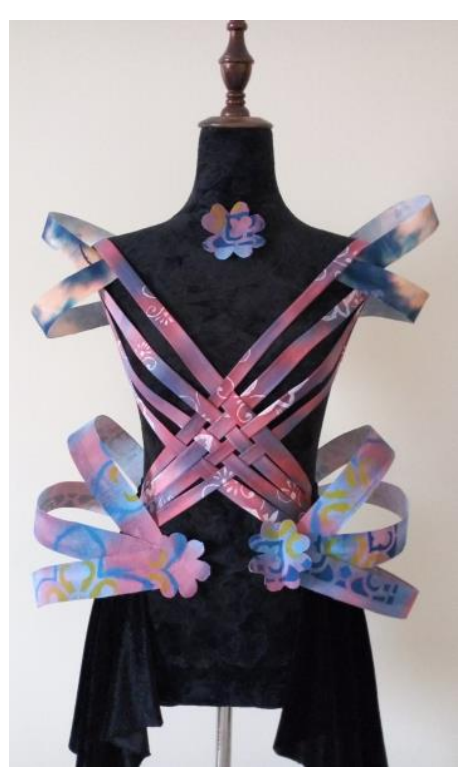

Fig. 8

(earthy - 3D)

(earthy - flat)

(earthy -flat)

Fig 1:4): Earthy fashion collection, flat and 3D ribbons, designed by author.

\subsection{Designing of the Study Instrument: Opinion Scale}

The Opinion Scale is designed to be applied on students of the Fashion Design program, the scale includes three axes, as follows:

The first axis: measures the psychological effect of fashion colours on the viewer psychology, and the axis contains (6) statements.

The second axis: measures the psychological effect of fashion originality on the student psychology and 
motivation for innovating, and the axis contains (5) statements.

The third axis: measures the generated motivation of students of fashion design program toward innovating a new trend of Arabic black abaya, which is decorated by mixed-colours ribbons, and the axis contains (2) statements.

The scale contains (13) statements. After designing the initial form of the scale, it was presented to a group of specialists in fashion design at Helwan University - Arab Republic of Egypt to ensure the reliability of the scale, and its suitability for application, the reliability of the scale was verified, and then the scale was put in its final form. The stability of the scale was confirmed by Cronbach's alpha as 0.73 , which confirms its validity for application.

\subsection{Instrument Applying: Opinion Scale}

The scale was designed by Google apps, and it was applied synchronously due to the pandemic conditions. May 15, 2021, was set for conducting the experiment.

The researcher presented the opinion scale and explained sentences to the study sample, (20) students. The researcher pretended that the objective of the experiment is to get the ranking ascending of the proposed designs, with the aim of not being affected by their emotions when viewing the designs.

A time was specified: two minutes for presenting the design and one minute for answering each statement, and therefore the total time for one design is (15) minutes, and the total time for the experiment is two hours. The evaluating was measured by Likert's three-point scale, so that the highest score for the scale is (39) and the lowest score is (13).

\section{STATISTICAL RESULTS}

The results of current study instrument, which is the student's opinion scale of fashion colours and originality, aiming to measure the psychological effects on a sample of fashion program students, statistics had been calculated within the score and percentage which obtained for each statement of the scale.

The following four tables representing the study variable, which are the colours collections: (rainbow- earthy) and originality: decorating by mixed colours ribbons (flat- 3D). The four tables are as follows: 1- (rainbow colours collection+ flat ribbons) 2-(rainbow colours collection+3D ribbons) 3- (earthy colours collection+ flat ribbons) 4- (earthy colours collection+3D ribbons). Through the statistics of student's responses, the study questions had been answered.

Table 1. The Psychological Effect of Fashion Colours and Fashion Originality on Fashion Design Program Students: Fashion collection (rainbow colours- flat decorating ribbons)

\begin{tabular}{|c|c|c|c|c|c|c|c|c|c|c|c|c|}
\hline \multirow[t]{3}{*}{ Statement } & \multicolumn{6}{|c|}{ Design (1) } & \multicolumn{6}{|c|}{ Design (2) } \\
\hline & \multicolumn{2}{|c|}{ A } & \multicolumn{2}{|c|}{$\mathrm{N}$} & \multicolumn{2}{|c|}{ DA } & \multicolumn{2}{|c|}{ A } & \multicolumn{2}{|c|}{$\mathrm{N}$} & \multicolumn{2}{|c|}{ DA } \\
\hline & $\mathrm{n}$. & $\%$ & $\mathrm{n}$. & $\%$ & $\mathrm{n}$. & $\%$ & $\mathrm{n}$. & $\%$ & $\mathrm{n}$. & $\%$ & $\mathrm{n}$. & $\%$ \\
\hline \multicolumn{13}{|l|}{ First axes: } \\
\hline 1 & 16 & 80 & 3 & 15 & 1 & 5 & 17 & 85 & 3 & 15 & 0 & 0 \\
\hline 2 & 17 & 85 & 2 & 10 & 1 & 5 & 18 & 90 & 2 & 10 & 0 & 0 \\
\hline 3 & 15 & 75 & 3 & 15 & 2 & 10 & 16 & 80 & 3 & 15 & 1 & 5 \\
\hline 4 & 0 & 0 & 2 & 10 & 18 & 90 & 1 & 5 & 3 & 15 & 16 & 80 \\
\hline 5 & 7 & 35 & 4 & 20 & 9 & 45 & 10 & 50 & 5 & 25 & 5 & 25 \\
\hline 6 & 3 & 15 & 3 & 15 & 14 & 70 & 6 & 30 & 4 & 20 & 10 & 50 \\
\hline Second axe & & & & & & & & & & & & \\
\hline
\end{tabular}


IJAEDU- International E-Journal of Advances in Education, Vol. VII, Issue 20, August, 2021

\begin{tabular}{|c|c|c|c|c|c|c|c|c|c|c|c|c|}
\hline 7 & 15 & 75 & 3 & 15 & 2 & 10 & 17 & 58 & 3 & 15 & 0 & 0 \\
\hline 8 & 2 & 10 & 2 & 10 & 16 & 80 & 0 & 0 & 20 & 100 & 0 & 0 \\
\hline 9 & 14 & 70 & 4 & 20 & 2 & 10 & 20 & 100 & 0 & 0 & 0 & 0 \\
\hline 10 & 11 & 55 & 6 & 30 & 3 & 15 & 15 & 75 & 3 & 15 & 2 & 10 \\
\hline 11 & 15 & 75 & 3 & 15 & 2 & 10 & 16 & 80 & 1 & 5 & 3 & 15 \\
\hline Third axes: & & & & & & & & & & & & \\
\hline 12 & 14 & 70 & 4 & 21 & 2 & 10 & 16 & 80 & 2 & 10 & 2 & 10 \\
\hline 13 & 16 & 80 & 3 & 15 & 1 & 5 & 15 & 75 & 3 & 15 & 2 & 10 \\
\hline
\end{tabular}

Table 2. The Psychological Effect of Fashion Colours and Fashion Originality on Fashion Design Program Students: Fashion collection (rainbow colours- 3D decorating ribbons)

\begin{tabular}{|c|c|c|c|c|c|c|c|c|c|c|c|c|}
\hline \multirow[t]{3}{*}{ Statement } & \multicolumn{6}{|c|}{ Design (3) } & \multicolumn{6}{|c|}{ Design (4) } \\
\hline & \multicolumn{2}{|c|}{ A } & \multicolumn{2}{|c|}{$\mathrm{N}$} & \multicolumn{2}{|c|}{ DA } & \multicolumn{2}{|c|}{ A } & \multicolumn{2}{|c|}{$\mathrm{N}$} & \multicolumn{2}{|c|}{ DA } \\
\hline & $\mathrm{n}$. & $\%$ & $\mathrm{n}$. & $\%$ & $\mathrm{n}$. & $\%$ & $\mathrm{n}$. & $\%$ & $\mathrm{n}$. & $\%$ & $\mathrm{n}$. & $\%$ \\
\hline \multicolumn{13}{|l|}{ First axes: } \\
\hline 1 & 18 & 90 & 2 & 10 & 0 & 0 & 19 & 95 & 1 & 5 & 0 & 0 \\
\hline 2 & 17 & 85 & 2 & 10 & 1 & 5 & 19 & 95 & 1 & 5 & 0 & 0 \\
\hline 3 & 17 & 85 & 2 & 10 & 1 & 5 & 17 & 85 & 2 & 10 & 1 & 5 \\
\hline 4 & 0 & 0 & 0 & 0 & 20 & 100 & 0 & 0 & 0 & 0 & 20 & 100 \\
\hline 5 & 11 & 55 & 7 & 35 & 2 & 10 & 12 & 60 & 5 & 25 & 3 & 15 \\
\hline 6 & 0 & 0 & 2 & 10 & 18 & 90 & 3 & 15 & 3 & 15 & 14 & 80 \\
\hline \multicolumn{13}{|l|}{ Second axes: } \\
\hline 7 & 17 & 85 & 2 & 10 & 1 & 0 & 19 & 95 & 1 & 5 & 0 & 0 \\
\hline 8 & 2 & 10 & 4 & 20 & 14 & 70 & 0 & 0 & 2 & 10 & 18 & 90 \\
\hline 9 & 18 & 90 & 2 & 10 & 0 & 0 & 13 & 65 & 5 & 25 & 2 & 10 \\
\hline 10 & 15 & 75 & 2 & 10 & 3 & 15 & 11 & 55 & 6 & 30 & 3 & 15 \\
\hline 11 & 17 & 85 & 2 & 10 & 1 & 5 & 17 & 85 & 3 & 15 & 0 & 0 \\
\hline \multicolumn{13}{|l|}{ Third axes: } \\
\hline 12 & 16 & 80 & 2 & 10 & 2 & 10 & 14 & 70 & 3 & 15 & 3 & 15 \\
\hline 13 & 13 & 65 & 5 & 25 & 2 & 10 & 12 & 60 & 3 & 15 & 5 & 25 \\
\hline
\end{tabular}


IJAEDU- International E-Journal of Advances in Education, Vol. VII, Issue 20, August, 2021

Table 3. The Psychological Effect of Fashion Colours and Fashion Originality on Fashion Design Program Students: Fashion collection (earthy colours- flat decorating ribbons)

\begin{tabular}{|c|c|c|c|c|c|c|c|c|c|c|c|c|}
\hline \multirow[t]{3}{*}{ Statement } & \multicolumn{6}{|c|}{ Design (5) } & \multicolumn{6}{|c|}{ Design (6) } \\
\hline & \multicolumn{2}{|c|}{ A } & \multicolumn{2}{|c|}{$\mathrm{N}$} & \multicolumn{2}{|c|}{ DA } & \multicolumn{2}{|c|}{ A } & \multicolumn{2}{|c|}{$\mathrm{N}$} & \multicolumn{2}{|c|}{ DA } \\
\hline & n. & $\%$ & $\mathrm{n}$. & $\%$ & n. & $\%$ & $\mathrm{n}$. & $\%$ & n. & $\%$ & n. & $\%$ \\
\hline \multicolumn{13}{|l|}{ First axes: } \\
\hline 1 & 1 & 5 & 5 & 25 & 14 & 80 & 3 & 15 & 5 & 10 & 12 & 60 \\
\hline 2 & 0 & 0 & 1 & 5 & 19 & 95 & 3 & 15 & 6 & 30 & 11 & 55 \\
\hline 3 & 2 & 10 & 2 & 10 & 16 & 80 & 7 & 35 & 8 & 40 & 5 & 25 \\
\hline 4 & 19 & 95 & 1 & 5 & 0 & 0 & 15 & 75 & 5 & 25 & 0 & 0 \\
\hline 5 & 19 & 95 & 1 & 5 & 0 & 0 & 12 & 60 & 7 & 35 & 1 & 5 \\
\hline 6 & 18 & 90 & 1 & 5 & 1 & 5 & 15 & 75 & 2 & 10 & 3 & 15 \\
\hline \multicolumn{13}{|l|}{ Second axes: } \\
\hline 7 & 17 & 85 & 2 & 10 & 1 & 5 & 17 & 85 & 3 & 15 & 0 & 0 \\
\hline 8 & 0 & 0 & 3 & 15 & 17 & 85 & 1 & 5 & 3 & 15 & 16 & 80 \\
\hline 9 & 17 & 85 & 3 & 15 & 0 & 0 & 15 & 75 & 4 & 20 & 1 & 5 \\
\hline 10 & 18 & 90 & 1 & 5 & 1 & 5 & 15 & 75 & 2 & 10 & 3 & 15 \\
\hline 11 & 12 & 60 & 3 & 15 & 5 & 25 & 18 & 90 & 2 & 10 & 0 & 0 \\
\hline \multicolumn{13}{|l|}{ Third axes: } \\
\hline 12 & 18 & 90 & 2 & 10 & 0 & 0 & 19 & 95 & 1 & 5 & 0 & 0 \\
\hline 13 & 20 & 100 & 0 & 0 & 0 & 0 & 18 & 90 & 1 & 5 & 1 & 5 \\
\hline
\end{tabular}

Table 4. The Psychological Effect of Fashion Colours and Fashion Originality on Fashion Design Program Students: Fashion collection (earthy colours- 3D decorating ribbons)

\begin{tabular}{|c|c|c|c|c|c|c|c|c|c|c|c|c|}
\hline \multirow[t]{3}{*}{ Statement } & \multicolumn{6}{|c|}{ Design (7) } & \multicolumn{6}{|c|}{ Design (8) } \\
\hline & \multicolumn{2}{|c|}{ A } & \multicolumn{2}{|c|}{$\mathrm{N}$} & \multicolumn{2}{|c|}{ DA } & \multicolumn{2}{|c|}{ A } & \multicolumn{2}{|c|}{$\mathrm{N}$} & \multicolumn{2}{|c|}{ DA } \\
\hline & $\mathrm{n}$. & $\%$ & $\mathrm{n}$. & $\%$ & $\mathrm{n}$. & $\%$ & $\mathrm{n}$. & $\%$ & $\mathrm{n}$. & $\%$ & $\mathrm{n}$. & $\%$ \\
\hline \multicolumn{13}{|l|}{ First axes: } \\
\hline 1 & 5 & 25 & 5 & 25 & 10 & 50 & 4 & 40 & 5 & 25 & 11 & 55 \\
\hline 2 & 2 & 10 & 2 & 10 & 16 & 80 & 3 & 15 & 2 & 10 & 15 & 75 \\
\hline 3 & 7 & 35 & 6 & 30 & 7 & 35 & 3 & 15 & 2 & 10 & 15 & 75 \\
\hline
\end{tabular}


IJAEDU- International E-Journal of Advances in Education, Vol. VII, Issue 20, August, 2021

\begin{tabular}{|c|c|c|c|c|c|c|c|c|c|c|c|c|}
\hline 4 & 18 & 90 & 2 & 10 & 0 & 0 & 14 & 70 & 4 & 20 & 2 & 10 \\
\hline 5 & 19 & 95 & 1 & 5 & 0 & 0 & 5 & 25 & 5 & 25 & 10 & 50 \\
\hline 6 & 17 & 85 & 2 & 10 & 1 & 5 & 10 & 50 & 7 & 35 & 3 & 15 \\
\hline Second axes: & & & & & & & & & & & & \\
\hline 7 & 18 & 90 & 2 & 10 & 0 & 0 & 14 & 70 & 4 & 20 & 2 & 10 \\
\hline 8 & 0 & 0 & 1 & 5 & 19 & 95 & 1 & 5 & 2 & 10 & 17 & 85 \\
\hline 9 & 17 & 85 & 2 & 10 & 1 & 5 & 16 & 80 & 2 & 10 & 2 & 10 \\
\hline 10 & 15 & 75 & 2 & 10 & 3 & 15 & 11 & 55 & 7 & 35 & 2 & 10 \\
\hline 11 & 18 & 90 & 2 & 10 & 0 & 0 & 14 & 70 & 4 & 20 & 2 & 10 \\
\hline Third axes: & & & & & & & & & & & & \\
\hline 12 & 17 & 85 & 2 & 10 & 1 & 5 & 10 & 50 & 5 & 25 & 5 & 25 \\
\hline 13 & 19 & 95 & 1 & 5 & 0 & 0 & 13 & 65 & 5 & 25 & 2 & 10 \\
\hline
\end{tabular}

\section{CONCLUSION}

The statistical results of Opinion Rating Scale 1) behind fashion colours: divided in two groups, rainbow colours fashion and earthy colours fashion, 2) behind fashion originality: divided in tow groups, decorating fashion with flat ribbons and decorating fashion with 3D ribbons, results indicated the tendency of fashion students toward the rainbow flat coloured ribbons as an approach to create a new trend of Arabic abaya, and this indicates also the positive psychological effect of creating new fashion trends even among conservative community, fashion in general represent an indicator of community desire and consideration toward change and developing.

\section{REFERENCE LIST}

Adams, F. M. Osgood, C. E. (1973). Across -Cultural Study of the active Meaning of Colour. Journal of Cross- Culture Psychology. (4)

Cash, T. F. Dawson, K. Davis, P. Bowen, M. Galumbek, C. (1989). Effect of cosmetics use on the physical attractiveness and body image of American college women. Journal of Social Psychology. (129)

Frank, M. G. Gilovich, T. (1988). The Dark Side of self and Self Perception: Black uniforms and aggression in professional sports. Journal of Personality and Social Psychology. (54)

Verij, A. (1997). Wearing Black Clothes: The Impact of Offenders and Suspect's Clothing on Impression Formation. Applied Cognitive Psychology. (4)

\section{APPENDIX}

Table of the Opinion Scale of the Psychological Effect of Fashion Colours Collections and Fashion Originality

\begin{tabular}{l|l} 
N. & Statement
\end{tabular}

First axes: Psychological effect of colours collections 
IJAEDU- International E-Journal of Advances in Education, Vol. VII, Issue 20, August, 2021

\begin{tabular}{|c|c|}
\hline 1 & I feel (happy) when seeing the design colours \\
\hline 2 & I feel (Enthusiastic) when seeing the design colours \\
\hline 3 & I feel (confident) when seeing design colours \\
\hline 4 & I feel (calm) when seeing design colours \\
\hline 5 & I feel (transcendent) when seeing design colours \\
\hline 6 & I feel (conservative) when seeing the design colours \\
\hline \multicolumn{2}{|c|}{ Second axes: Psychological effect of originality } \\
\hline 7 & I feel (impressed) when seeing the design details \\
\hline 8 & I feel (annoyed) when seeing the design details \\
\hline 9 & I feel (inspired) when seeing the design details \\
\hline 10 & I feel (enthusiastic to develop) when seeing the design details \\
\hline 11 & I feel (desired to implement) when seeing the design details \\
\hline \multicolumn{2}{|r|}{ Third axes: Motivation to design an original Abaya decorated with colourful ribbons } \\
\hline 12 & $\begin{array}{l}\text { I am looking forward to designing an Arabic black abaya inspired by the design colours } \\
\text { collection }\end{array}$ \\
\hline 13 & I am looking forward to designing an Arabic black abaya inspired by the design lines details. \\
\hline
\end{tabular}

